\title{
Vertebral artery injury in C1-2 transarticular screw fixation: results of a survey of the AANS/CNS Section on Disorders of the Spine and Peripheral Nerves
}

Neill M. Wright, M.D., and Carl Lauryssen, M.D.

Department of Neurosurgery, Washington University School of Medicine, St. Louis, Missouri

Object. The 847 active members of the American Association of Neurological Surgeons/Congress of Neurological Surgeons (AANS/CNS) Section on Disorders of the Spine and Peripheral Nerves were surveyed to quantitate the risk of vertebral artery (VA) injury during C1-2 transarticular screw placement.

Methods. This retrospective study elicited the number of patients treated with transarticular screws, the number of screws placed, the incidence of VA injury and subsequent neurological deficit, and the management of known or suspected VA injury.

Two hundred thirteen $(25.1 \%)$ of the 847 surgeons responded. One hundred one respondents (47.4\%) had placed a total of $2492 \mathrm{C} 1-2$ transarticular screws in 1318 patients. Thirty-one patients (2.4\%) had known VA injuries and an additional 23 patients (1.7\%) were suspected of having injuries. However, only two (3.7\%) of the 54 patients with known or suspected VA injuries exhibited subsequent neurological deficits and only one (1.9\%) died from bilateral VA injury. Other iatrogenic complications included dural tears, screw fractures, screw breakout, fusion failure, infection, and suboccipital numbness.

Conclusions. Including both known and suspected cases, the risk of VA injury was $4.1 \%$ per patient or $2.2 \%$ per screw inserted. The risk of neurological deficit from VA injury was $0.2 \%$ per patient or $0.1 \%$ per screw, and the mortality rate was $0.1 \%$. The choice of management of intraoperative VA injuries was evenly divided between placing the patient under observation and initiating immediate postoperative angiography with possible balloon occlusion.

Key Words * vertebral artery injury * spine instrumentation * transarticular screw fixation

Instability of the atlantoaxial complex poses special stabilization challenges compared with the remainder of the cervical spine. The unique architecture of the atlantoaxial complex, with its horizontal articular surfaces, ligamentous connections, and distinctive vertebral anatomy, allows not only flexion, extension, and lateral bending, but also significant axial rotation.[24] The higher failure rate of both external immobilization and surgical fusion in treating atlantoaxial instability, compared with failure in treating the remainder of the cervical spine, arises in part from this rotational capability.[9]

Atlantoaxial instability can be resolved by a wide variety of surgical techniques, including anterior 
odontoid screw fixation[3] or posterior fusion methods such as the Gallie-type fusion,[10] Brooks-Jenkins' technique,[4] interlaminar clamps,[18] or Sonntag's modified Gallie fusion.[7] Over the past decade, the C1-2 transarticular screw technique developed by Magerl and Seemann[21] has become increasingly popular because of its greater biomechanical stability and superior fixation of atlantoaxial rotation. $[13,16]$ In several clinical series[14,19,20,22,27] the success of the transarticular screw technique has been demonstrated, with fusion rates ranging from 87 to $100 \%$. However, despite the increased stability provided by the transarticular screw technique, the variable anatomy of the atlantoaxial complex often limits its use. Specifically, the course of the vertebral artery (VA) and the nonconstant size and location of the transverse foramen in the lateral mass of both the atlas and axis place the VA at risk during drilling or screw placement.

Recent anatomical studies of the atlantoaxial complex suggest that up to $20 \%$ of patients have an atlantoaxial anatomy that precludes safe screw placement.[20,25] Few clinical series have demonstrated vascular injury, despite the fact that bilateral screws were placed in nearly all patients. Other reported complications of this technique include hypoglossal nerve paresis, suboccipital numbness caused by C-2 root injury, dural tears, screw malpositioning, screw fracture, failure of fusion, and wound infection. Because of this discrepancy between earlier clinical reports and more recent anatomical studies, a retrospective survey of the risk of VA injury during transarticular screw placement was undertaken.

\section{CLINICAL MATERIAL AND METHODS}

\section{Survey Recipients}

A retrospective survey was mailed in February 1997 to all 847 active members of the American Association of Neurological Surgeons/Congress of Neurological Surgeons (AANS/CNS) Section on Disorders of the Spine and Peripheral Nerves, as identified from the membership roster in the 1996 section program book from the 12th annual meeting.

\section{Definitions of Terms}

Recipients were asked to provide the number of cases of both known and suspected VA injury. Known VA injury involved profuse arterial bleeding or was confirmed by postoperative angiography. Suspected cases of VA injury included those cases in which bleeding of indeterminate origin was encountered but no confirmatory studies were performed.

\section{Survey Questions}

Each survey recipient was asked to provide the following information: 1) total number of patients treated with transarticular screws; 2) total number of transarticular screws placed; 3) incidence of known VA damage that occurred intraoperatively; 4) incidence of suspected VA damage; 5) choice of management of known or suspected vessel injury (observation, surgical ligation of the damaged vessel, primary repair of the damaged vessel, angiography, or balloon embolization); 6) incidence of neurological injury arising from a known or suspected iatrogenic VA injury, and the type of deficit; and 7) incidence of other complications of screw placement (dural tear, hypoglossal nerve injury, or suboccipital numbness).

Details of individual surgical techniques were not included within the scope of this survey, beyond those management issues addressed earlier. All surgeons were asked to return the survey, even if transarticular screw fixation was not part of their practice. Surgeons were given the option of responding anonymously to encourage full disclosure of adverse outcomes. 


\section{Statistical Analysis}

All surveys returned by June 1, 1997 were evaluated. Surveys were returned by both mail and telephone facsimile. Results were tabulated and statistically analyzed. Student's paired t-test (SigmaPlot, Version 1.02; Jandel Scientific, San Rafael, CA) was used to determine statistical significance.

\section{RESULTS}

\section{Survey Respondents}

Two hundred twenty-five (26.6\%) of the 847 surveys were returned by June 1, 1997, either by mail or telephone facsimile. Twelve $(5.3 \%)$ of these surveys were returned as undeliverable with no known forwarding addresses. One hundred one respondents $(47.4 \%)$ had performed transarticular screw fixation of the atlantoaxial complex in their practices, whereas $112(52.5 \%)$ had not.

Although most respondents identified themselves, 39 (18.3\% of all respondents) responded anonymously. The anonymous replies were nearly evenly distributed between surgeons who had performed the procedure (22 surgeons [56.4\% of anonymous responders]) and those who had not (17 surgeons [43.6\%]). Of the surgeons who had performed the procedure $21.8 \%$ responded anonymously; of the surgeons not performing transarticular screw fixation, $15.2 \%$ responded anonymously.

The respondents represent both academic centers and private practice. Although the number of anonymous respondents prevents an exact count, at least 50 academic centers were represented. The vast majority of the respondents practice in the United States or Canada.

\section{Number of Patients Treated}

A total of 1318 patients were treated by the 101 surgeons who had used the transarticular screw technique. The mean number of patients treated by each surgeon was 13 (standard deviation [SD] 18, standard error of the mean [SEM] 1.8), with a range of one to 112.

\section{Number of Transarticular Screws Placed}

A total of 2492 C1-2 transarticular screws were placed in the 1318 patients, an average of 1.9 screws per patient. The number of patients who underwent bilateral screw placement was $1174(89.1 \%)$, whereas the number in whom only unilateral screws were placed was $144(10.9 \%)$. The mean number of screws placed per surgeon was 24.7 (SD 33.3, SEM 3.3), with a range of one to 205.

\section{Vertebral Artery Injury}

Incidence of Known VA Injury. Sixteen (15.8\%) of the surgeons who had performed the procedure reported at least one case of known VA injury during screw placement. A total of 31 cases of known VA injuries were reported. Known VA injuries constituted $1.2 \%$ per transarticular screw placed and $2.4 \%$ per patient treated.

Although surgeons more experienced in the technique had slightly lower rates of known VA injury, this difference was not statistically significant. This lack of statistical significance was consistent when using thresholds of $10(1.6 \%$ per patient compared with $2.5 \%, \mathrm{p}=0.79), 15(2 \%$ compared with $2.2 \%, \mathrm{p}=$ $0.87)$, or $20(2.1 \%$ compared with $2.2 \%, \mathrm{p}=0.88)$ patients as a measure of familiarity with treating the technique. 
Four $(25 \%)$ of the surgeons who reported known VA injuries did so anonymously.

Incidence of Suspected VA Injury. Twenty (19.8\%) of the surgeons who had performed the C1-2 transarticular screw procedure reported at least one case of suspected, but unconfirmed, VA injury during screw placement. A total of 23 cases of suspected VA injury were reported. The rate of suspected VA injury per transarticular screw placed was $0.8 \%$ and the rate per patient treated was $1.7 \%$.

Again, although surgeons more familiar with the technique had slightly lower rates of suspected VA injury compared with those with less experience, this was not statistically significant with a threshold of $10(1.9 \%$ compared with $2.3 \%, \mathrm{p}=0.91), 15(1.5 \%$ compared with $2.4 \%, \mathrm{p}=0.56)$, or $20(1.7 \%$ compared with $2.3 \%, \mathrm{p}=0.96)$ patients treated as a measure of familiarity with the technique.

Three (15\%) of the surgeons who reported suspected cases of VA injury did so anonymously.

Total Incidence of VA Injury (Known and Suspected). Thirty surgeons (29.7\%) with experience using the technique reported cases of either known or suspected VA injury during C1-2 transarticular screw placement. Fifty-four cases were reported. The total rate of known or suspected VA injuries per transarticular screw inserted was $2.2 \%$ and the rate per patient treated was $4.1 \%$. Once again, although surgeons more familiar with the technique reported slightly lower total rates of VA injury, this was not statistically significant, regardless of whether a threshold of $10(3.5 \%$ compared with $4.7 \%, \mathrm{p}=0.81), 15$ (3.6\% compared with $4.6 \%, \mathrm{p}=0.59)$, or $20(3.8 \%$ compared with $4.4 \%, \mathrm{p}=0.92)$ patients treated was used as a measure of familiarity.

Seven $(23.3 \%)$ of the surgeons who reported either known or suspected VA injury did so anonymously.

\section{Neurological Injury Arising From Known or Suspected VA Injury}

Only three patients were reported to have suffered neurological sequelae from iatrogenic VA injury. One patient died from bilateral VA injury resulting in brainstem ischemia. The other patients incurred unilateral cerebellar strokes: one occurred after a known VA injury, and the other occurred 6 to 8 weeks postoperatively in a patient with suspected VA injury.

The risk of neurological injury was $0.1 \%$ per transarticular screw placed or $0.2 \%$ per patient treated. The risk of a known or suspected VA injury caused by screw placement leading to neurological deficit was only $3.7 \%$. The single death resulted in a mortality rate of $0.1 \%$.

Only one case of neurological deficit, a cerebellar stroke, was reported anonymously.

\section{Other Complications of Screw Placement}

Failure of fusion occurred in three patients $(0.2 \%)$. Intraoperative dural tears were encountered in four patients $(0.3 \%)$. Five patients $(0.4 \%)$ had screws breakout at the atlantoaxial complex and 10 patients $(0.8 \%)$ had screw fractures. Infection occurred in six patients $(0.5 \%)$ and one patient $(0.1 \%)$ required removal of a screw because of persistent suboccipital neuralgia. No patient was reported to have hypoglossal paresis.

By far the most common complication was suboccipital numbness. Seventeen (16.8\%) of the respondents who had performed transarticular screw fixation reported either transient or permanent suboccipital numbness in their patients. Some of these surgeons had rates of suboccipital numbness as high as 50\%; however, most noted that this typically resolved in a matter of weeks or months. One respondent reported 
often intentionally sectioning the C-2 root to visualize the C1-2 facet joint more clearly.

\section{Choice of Management of Known or Suspected VA Injury}

A total of 70 respondents (32.9\%), including surgeons experienced in transarticular screw fixation (55 surgeons) and those who had not yet used the technique (15 surgeons), offered guidelines for management of known or suspected VA injury. Most respondents recommended either observation alone, with further treatment dictated by the patient's postoperative clinical course (29 surgeons [41.4\%]), or immediate postoperative angiography and possible balloon embolization of a damaged vessel (29 surgeons [41.4\%]). However, a smaller number advocated attempted primary repair of the VA (six surgeons [8.6\%]), surgical ligation of the damaged artery (three surgeons [4.3\%]), or other management options (three surgeons [4.3\%]).

Fifty-five (54.5\%) of the 101 surgeons who had experience using the transarticular screw technique responded with suggestions regarding management of suspected or known VA injury. After intraoperative control of bleeding, which was accomplished by either placing the screw in such a way as to occlude the bleeding drill hole or plugging the hole with bone wax, 25 respondents $(45.5 \%)$ suggested postoperative observation alone with further care dictated by the patient's clinical course. Twenty-two respondents (40\%) advocated immediate postoperative angiography with possible balloon embolization of a damaged vessel. Four (7.3\%) surgeons recommended attempting primary repair of the injured VA, and one $(1.8 \%)$ endorsed surgical ligation of the damaged artery. Three respondents $(5.5 \%)$ had no empirical recommendations, but would choose from the aforementioned options based on the clinical scenario.

Fifteen (13.4\%) of the 112 respondents not experienced with the transarticular screw technique also proffered suggestions regarding management of known or suspected VA injury. Seven $(46.7 \%)$ advocated immediate postoperative angiography with possible balloon embolization, whereas four (26.7\%) suggested observation alone with further intervention depending on the patient's clinical course. Two surgeons $(13.3 \%)$ recommended surgical ligation of the damaged VA, whereas two (13.3\%) endorsed attempting primary repair.

\section{DISCUSSION}

Surgical attempts at stabilization of the atlantoaxial complex date back to 1910, when Mixter and Osgood[23] first described securing the posterior elements of the atlas and axis with heavy silk thread in a case of traumatic instability. Since that time, other posterior fusion techniques have been advocated, such as the Gallie fusion,[10] the Brooks-Jenkins fusion,[4] the interlaminar clamp,[18] and Sonntag's modified Gallie fusion.[7] Despite these advances, posterior fusion failure rates can be as high as $25 \%$ when treating atlantoaxial injuries,[6] especially in cases with rotational instability.

The surgical technique described by Magerl and Seemann,[21] which includes direct fixation of the atlas and axis with transarticular screws (Fig. 1), has increasingly been used to treat patients with significant rotatory instability of the atlantoaxial complex. 

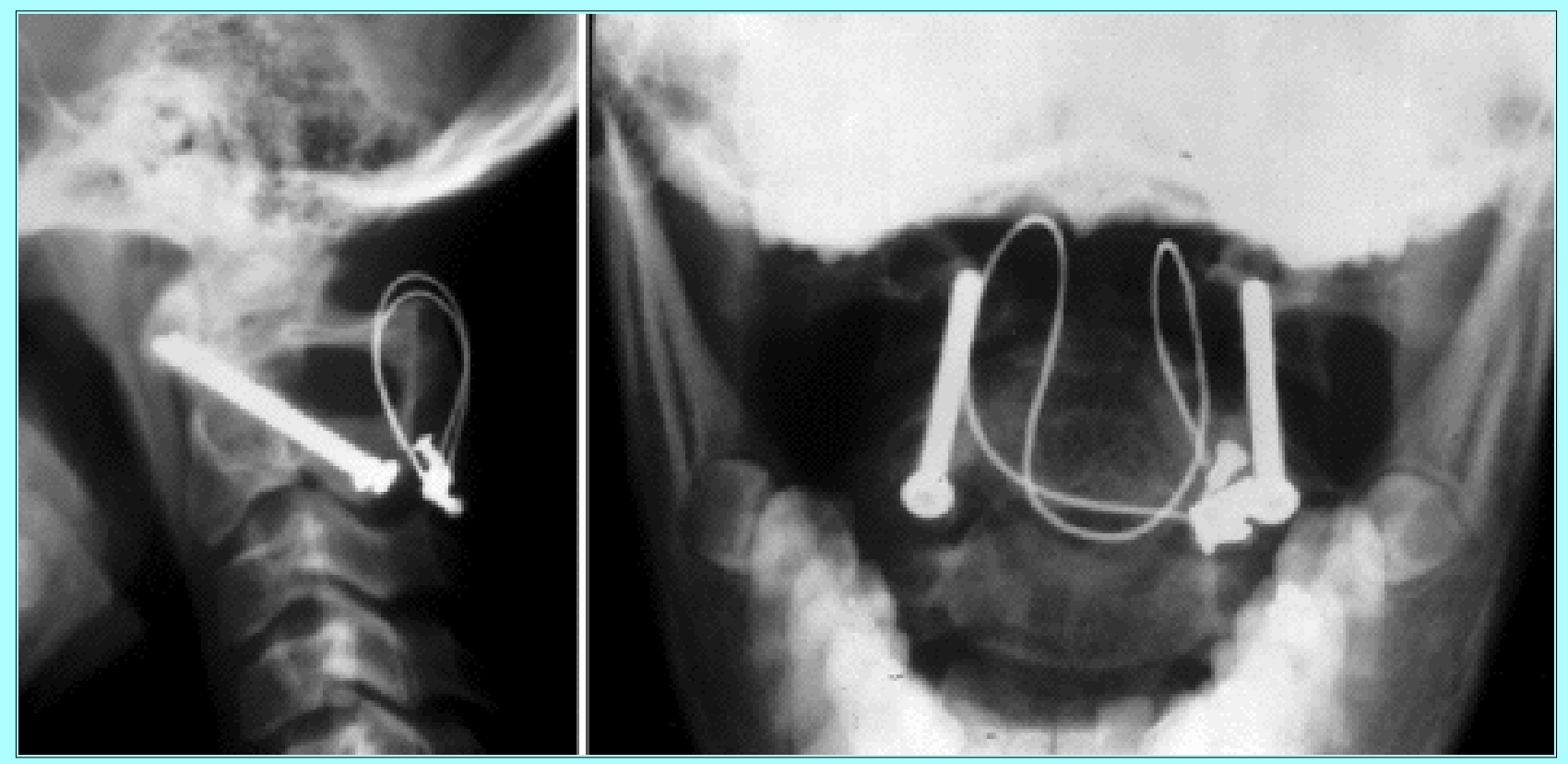

Fig. 1. Left: Lateral radiograph revealing atlantoaxial stabilization with bilateral transarticular screws supplemented by Sonntag's modified Gallie fusion. Right: Anteroposterior radiograph demonstrating atlantoaxial stabilization with bilateral transarticular screws supplemented by Sonntag's modified Gallie fusion.

Biomechanical studies on cadaveric spines have shown Magerl transarticular screw fixation to provide significantly more stability in axial rotation than other posterior fusion techniques and to prove equally stable in flexion, extension, and lateral bending. $[13,16]$ Previous retrospective clinical trials reported by Grob and colleagues[14] and Jeanneret and Magerl,[19] and prospective trials by Marcotte and associates[22] and Stillerman and Wilson[27] have shown excellent fusion rates and remarkably low morbidity (Table 1).

\begin{tabular}{|c|c|c|c|c|c|c|c|c|c|}
\hline \multirow[b]{3}{*}{ Authors \& Year } & \multirow[b]{3}{*}{$\begin{array}{l}\text { No. of } \\
\text { Patients }\end{array}$} & \multicolumn{2}{|r|}{$\begin{array}{l}\text { TABLE } 1 \\
\text { IN PUBLISHED }\end{array}$} & \multicolumn{5}{|c|}{ ANSARTICULAR SCREW FIXATION* } & \\
\hline & & \multicolumn{2}{|c|}{ No. of Patients [\%] } & \multicolumn{6}{|c|}{ No. of Complications } \\
\hline & & Bilat Procedures & Successfu F usions & $\begin{array}{l}\text { Pseud } \\
\text { artlrosis }\end{array}$ & $\begin{array}{l}\text { CNXII } \\
\text { Paresis }\end{array}$ & $\begin{array}{l}\text { Suboc } \\
\text { Numbt }\end{array}$ & $\begin{array}{c}\text { Dural } \\
\text { Tear }\end{array}$ & $\begin{array}{l}\text { Broken } \\
\text { Scre'w }\end{array}$ & $\begin{array}{l}\text { YA } \\
\text { Iri wy }\end{array}$ \\
\hline $\begin{array}{c}\text { Grob, et al., } \\
1991\end{array}$ & 161 & $161(100)$ & $153(95)$ & 1 & $1 \ddagger$ & 0 & 0 & 3 & 0 \\
\hline $\begin{array}{l}\text { Jeanneret \& } \\
\text { Mager, } 1992\end{array}$ & 12 & $12(100)$ & $12(100)$ & 0 & $1 \mp$ & 0 & 0 & 0 & 0 \\
\hline $\begin{array}{l}\text { Marootte, et al., } \\
1993\end{array}$ & 18 & $17(94.4)$ & $17(100)$ & 0 & 0 & 0 & 2 & 0 & 0 \\
\hline $\begin{array}{l}\text { Stillerman \& } \\
\text { Uúlson, } 1993\end{array}$ & 20 & $19(95.0)$ & $19(95)$ & 0 & 0 & 2 & 0 & 0 & 0 \\
\hline $\begin{array}{l}\text { Madawi, et al., } \\
1997\end{array}$ & 61 & $60(98.4)$ & $53(86.9)$ & 8 & 1 & 0 & 0 & 5 & 5 \\
\hline total no. (\%) & 272 & $\begin{array}{r}269 \text { of } 272 \\
(98.9) \\
\end{array}$ & $\begin{array}{r}254 \text { of } 271 \\
(93.7) \S \\
\end{array}$ & $\begin{array}{c}9 \\
(3.3)\end{array}$ & $\begin{array}{c}3 \\
(1.1) \\
\end{array}$ & ${ }^{2}$ & $\begin{array}{c}2 \\
(0.7)\end{array}$ & $\begin{array}{c}8 \\
(2.9)\end{array}$ & $\begin{array}{c}5 \\
(1.8) \\
\end{array}$ \\
\hline \multicolumn{10}{|c|}{ 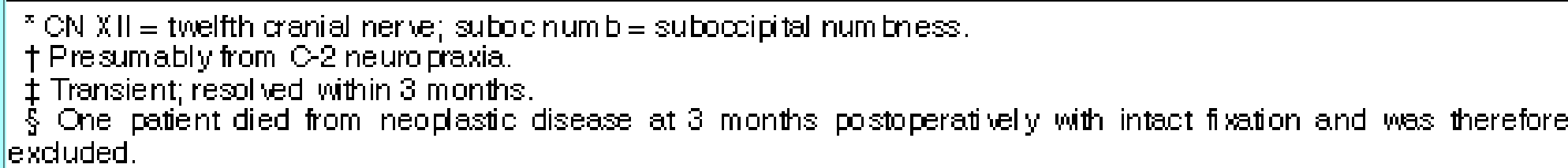 } \\
\hline
\end{tabular}


Nevertheless, the normal anatomy of the atlantoaxial complex requires exact screw placement to prevent trauma to the VA. The typical course of the VA carries the vessel in proximity to the ideal screw trajectory[28] (Fig. 2). Additionally, the incidence of VA anomalies in the atlantoaxial region is $2.3 \% .[29]$

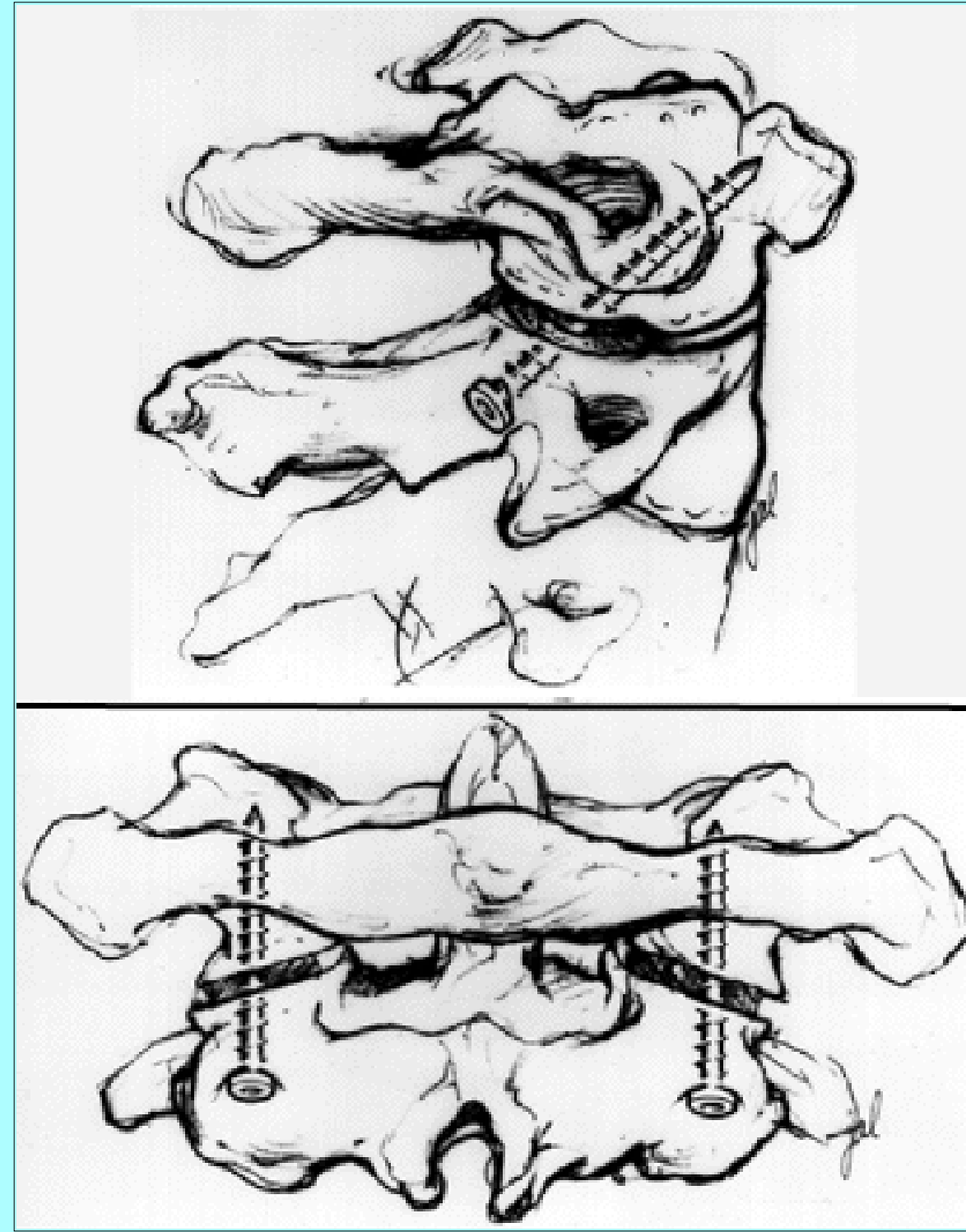

Fig. 2. Upper: Illustration (lateral perspective) of the atlantoaxial complex, with transarticular screws in place, showing the proximity of the screw to the transverse foramen of both the atlas and axis. Lower: Illustration (anteroposterior perspective) displaying the atlantoaxial complex. The transarticular screws are situated immediately medial to the VA groove.

Moreover, it has been shown in recent radiological and anatomical studies of the atlantoaxial complex that up to $20 \%$ of the population may have anomalous positioning of the VA, which would preclude safe bilateral screw placement.[20,25] Paramore, et al.,[25] reviewed nearly 100 fine-slice axial computerized tomography scans of the C1-2 complex and found that $18 \%$ showed a high-riding C-2 transverse foramen on at least one side, which placed the VA at significant risk, even with "ideal" screw placement. More recently, Madawi, et al.,[20] performed anatomical measurements on 25 isolated C-2 vertebrae and found $20 \%$

to have a pedicle anatomy that prevented safe screw placement.

The importance of preoperative radiographic imaging in patients in whom transarticular screw fixation of the atlantoaxial complex is planned, including fine-slice axial computerized tomography scans of the C1-2 complex, to assess not only VA anatomy, but also the physical dimensions of the C-2 pedicle has previously been reported.[8] In addition, the importance of anatomical reduction of the injured atlantoaxial complex in reducing the risk of VA injury has been discussed by Madawi, et al.[20] All of the patients in their series who experienced injury to the VA had undergone incomplete reduction.

No authors of earlier clinical trials[14,19,22,27] reported VA injury despite placing screws bilaterally in 94.4 to $100 \%$ of their patients, leading to an apparent discrepancy between findings of clinical trials and radiological and anatomical studies. However, anecdotal reports of VA injury have been reported.[1,5] Madawi, et al.,[20] in their recent retrospective review of 61 patients treated with transarticular screw fixation, reported five patients who sustained intraoperative VA injuries; one patient incurred a nonfatal brainstem infarction, for a relative risk of VA injury of $8.2 \%$. All but one of their 61 patients were treated 
using bilateral screws. The AANS/CNS survey was undertaken to assess more clearly the quantitative risk of VA injury as well as the risk of subsequent neurological deficit.

The retrospective survey of atlantoaxial transarticular fusion in 161 patients by 10 surgeons from four centers in Switzerland, conducted by Grob and colleagues[14] has been widely cited in both neurosurgical and orthopedic literature. With over 1300 patients, eight times more than the Grob study, the AANS/CNS survey represents the largest reported series of transarticular screw fixation to date. More than 100 neurosurgeons from both academic centers and private practice who used this technique responded. Although any questionnaire carries the risk of self-reporting bias, the number of respondents and the option of responding anonymously were thought to minimize this potential drawback.

Although response rate of $26.6 \%$ to the questionnaire precludes an exact determination of the incidence of VA injury during C1-2 transarticular screw placement, this survey serves as an estimation of the actual risk. Although the survey recipients, all active members of the AANS/CNS Section on Disorders of the Spine and Peripheral Nerves, were thought to represent the subset of neurosurgeons most likely to be familiar with the transarticular screw technique, the low response rate likely is due to the relatively recent introduction of this technique. The response from academic neurosurgeons was disproportionally high, with at least 50 academic centers represented.

Of the patients in this series, $10.9 \%$ underwent unilateral screw placement only. Although this series represents a smaller percentage of patients in whom bilateral screws were placed than previous clinical series, there is still less than an 18 to $20 \%$ risk for VA injury from bilateral screw placement, as suggested by the aforementioned anatomical and radiological studies.

With 54 reported cases of known or suspected intraoperative VA injury, the total risk was $2.2 \%$ per screw placed or $4.1 \%$ per patient treated. This is somewhat lower than the $8.2 \%$ risk of VA injury recently reported by Madawi, et al.[20] Although the rates of VA injury (suspected, known, or the two combined) in the hands of surgeons more experienced with the technique were lower than those less familiar with the procedure, the lack of statistical significance was surprising. However, the admonition given in previous clinical reports of transarticular screw fixation that this procedure should not be performed by an inexperienced surgeon was stressed by many respondents. Although a small percentage of respondents replied anonymously, their rates of reporting VA injury were similar to those who identified themselves.

Reassuringly, aside from the one patient who died only two (3.7\%) of the 54 patients with known or suspected injury suffered neurological injury as a result of the damaged VA. Both of these patients incurred cerebellar strokes, one after a known VA injury and the other 6 to 8 weeks postoperatively after a suspected injury. Thus, the risk of neurological injury as a result of VA trauma during screw fixation was $0.1 \%$ per screw or $0.2 \%$ per patient. Even in patients with clear damage to the VA during drilling or transarticular screw placement, the risk of neurological deficit is still quite low. The single death in this series resulted in a mortality rate of $0.1 \%$.

The low incidence of neurological deficit arising from VA injury is supported by earlier reported series of VA trauma. Previous clinical reviews[15] have provided discussion of the risk of VA dissection leading to transient ischemic attacks, stroke, or death. Experience with traumatic vascular injuries has shown that ligation or embolization of a unilateral VA is often tolerated well, with an incidence of neurological sequelae ranging from zero[12,31] to 6.25\%.[17] It has been demonstrated in extensive series of vertebrobasilar aneurysms treated by proximal artery ligation $[2,15,26]$ that the risk of 
neurological injury from vertebrobasilar ischemia ranges from 2.7[26] to 6.7\%[15] when a unilateral VA is occluded. The risk of neurological deficit was thought to be minimal when the contralateral VA is patent and the posterior communicating arteries are of adequate patency and diameter. The importance of the posterior communicating arteries is underscored by the finding that vertebrobasilar ischemia only resulted in up to $20 \%$ of patients treated with bilateral VA occlusions.[26]

Many respondents agreed that intraoperative bleeding should be controlled by placing the screw into the drilled hole or occluding the drill hole with bone wax, although some surgeons advocated attempting primary repair of the VA. Golfinos and colleagues[11] previously reported on primary repair of the VA during anterior approaches to the cervical spine. Others have suggested surgical ligation of the damaged vessel. It is important to reiterate the conclusions of previous authors[1] that, if VA injury is suspected on drilling or placing the first screw, the remaining side must be left inviolate so as to preclude bilateral VA injury. The sole death cited by a respondent occurred as a result of bilateral VA damage.

Opinions regarding postoperative management of known or suspected VA injury were primarily split into two equal groups. The first group recommended postoperative observation alone after controlling bleeding intraoperatively. Further intervention would then be dictated by the patient's clinical course. The other group advocated proceeding to angiography in the immediate postoperative period with possible balloon embolization if a damaged vessel was discovered.

The cases of neurological injury cited by the respondents arose from different causes. The cerebellar stroke that occurred in the immediate postoperative period likely resulted from complete occlusion resulting in ischemia. However, the other neurological complication, which was also a cerebellar stroke, occurred nearly 2 months postoperatively, presumably as a result of emboli from a partially occluded VA.

The rates of other reported complications cited in this survey parallel those reported in previous studies. Bone fusion was successful in all but two patients, for a fusion rate of $99.8 \%$. The rates of dural tear, screw breakout, screw fracture, and infection were all individually less than $1 \%$. No patient had hypoglossal paresis. However, many surgeons reported cases in which patients exhibited transient or permanent suboccipital numbness and one patient required screw removal as a result of prolonged suboccipital neuralgia.

Frameless stereotactic guidance may further lower the morbidity and mortality rates involved in transarticular screw placement because the guidance images provided by current stereotactic systems lend themselves well to transarticular screw fixation.[30] Recently investigators in one small series of 11 patients who were stabilized with transarticular screws placed with the aid of a frameless stereotactic guidance system reported no complications of screw placement (Foley K, Smith M: unpublished data).

\section{CONCLUSIONS}

The transarticular screw fixation technique has become increasingly popular because it provides improved biomechanical stability to the atlantoaxial complex. However, up to $20 \%$ of the population have normal anatomical variations that place them at risk for bilateral screw placement, and only case reports of VA injury have been published. In this large survey of neurosurgical experience with transarticular screw fixation, the risk of VA injury during screw placement is $4.1 \%$ per patient treated or $2.2 \%$ per screw inserted. The risk of subsequent neurological deficit from iatrogenic VA injury is small.

\section{Acknowledgments}


We thank all of the members of the AANS/CNS Section on Disorders of the Spine and Peripheral Nerves for their cooperation with this survey, especially Drs. R. Apfelbaum, N. Baldwin, H. Bartkowski, E. Blinderman, J. Bonner, I. Chambi, R. Chesnut, R. Dunker, M. Hadley, J. Harrington, F. Henderson, L. Leibrock, J. Lindley, T. Lovely, D. McBride, H. Morgan, B. Mullin, D. Neagoy, D. Nehls, K. Ott, S. Palmer, S. Papadopoulos, C. Paramore, N. Perin, D. Prolo, G. Rodts, Jr., S. Shapiro, V. Sonntag, D. Vollmer, J. Wilson, and E. Woodard. We would also like to thank Dr. Ralph G. Dacey, Jr., for his review of the manuscript.

\section{References}

1. Apfelbaum RI: Screw fixation of the upper cervical spine: indications and techniques. Contemp Neurosurg 16:1-8, 1994

2. Aymard A, Gobin YP, Hodes JE, et al: Endovascular occlusion of vertebral arteries in the treatment of unclippable vertebrobasilar aneurysms. J Neurosurg 74:393-398, 1991

3. Böhler J: Anterior stabilization for acute fractures and non-unions of the dens. J Bone Joint Surg (Am) 64:18-27, 1982

4. Brooks AL, Jenkins EB: Atlanto-axial arthrodesis by the wedge compression method. J Bone Joint Surg (Am) 60:279-284, 1978

5. Coric D, Branch CL Jr, Wilson JA, et al: Arteriovenous fistula as a complication of C1-2 transarticular screw fixation. Case report and review of the literature. J Neurosurg 85:340-343, 1996

6. Coyne TJ, Fehlings MG, Wallace MC, et al: C1-C2 posterior cervical fusion: long-term evaluation for results and efficacy. Neurosurgery 37:688-693, 1995

7. Dickman CA, Sonntag VKH, Papadopoulos SM, et al: The interspinous method of posterior atlantoaxial arthrodesis. J Neurosurg 74:190-198, 1991

8. Dull ST, Toselli RM: Preoperative oblique axial computed tomographic imaging for C1-C2 transarticular screw fixation: technical note. Neurosurg 37:150-152, 1995

9. Fried LC: Atlanto-axial fracture-dislocations. Failure of posterior C.1 to C.2 fusion. J Bone Joint Surg (Br) 55:490-496, 1973

10. Gallie WE: Fractures and dislocations of the cervical spine. Am J Surg 46:495-499, 1939

11. Golfinos JG, Dickman CA, Zabramski JM, et al: Repair of vertebral artery injury during anterior cervical decompression. Spine 19:2552-2556, 1994

12. Golueke P, Sclafani S, Phillips T, et al: Vertebral artery injury--diagnosis and management. J Trauma 27:856-865, 1987

13. Grob D, Crisco JJ III, Panjabi MM, et al: Biomechanical evaluation of four different posterior atlantoaxial fixation techniques. Spine 17:480-490, 1992

14. Grob D, Jeanneret B, Aebi M, et al: Atlanto-axial fusion with transarticular screw fixation. J Bone Joint Surg (Br) 73:972-976, 1991 
15. Halbach VV, Higashida RT, Dowd CF, et al: Endovascular treatment of vertebral artery dissections and pseudoaneurysms. J Neurosurg 79:183-191, 1993

16. Hanson PB, Montesano PX, Sharkey NA, et al: Anatomic and biomechanical assessment of transarticular screw fixation for atlantoaxial instability. Spine 16:1141-1145, 1991

17. Higashida RT, Halbach VV, Tsai FY, et al: Interventional neurovascular treatment of traumatic carotid and vertebral artery lesions: results in 234 cases. AJR 153:577-582, 1989

18. Holness RO, Huestis WS, Howes WJ, et al: Posterior stabilization with an interlaminar clamp in cervical injuries: technical note and review of the long term experience with the method. Neurosurgery 14:318-322, 1984

19. Jeanneret B, Magerl F: Primary posterior fusion C1-2 in odontoid fractures: indications, technique, and results of transarticular screw fixation. J Spinal Disord 5:464-475, 1992

20. Madawi AA, Casey ATH, Solanki GA, et al: Radiological and anatomical evaluation of the atlantoaxial transarticular screw fixation technique. J Neurosurg 86:961-968, 1997

21. Magerl F, Seemann PS: Stable posterior fusion of the atlas and axis by transarticular screw fixation, in Kehr P, Weidner A (eds): Cervical Spine I. Vienna: Springer-Verlag, 1987, pp 322-327

22. Marcotte P, Dickman CA, Sonntag VKH, et al: Posterior atlantoaxial facet screw fixation. J Neurosurg 79:234-237, 1993

23. Mixter SJ, Osgood RB: Traumatic lesions of the atlas and axis. Ann Surg 51:193-207, 1910

24. Panjabi M, Dvorak J, Duranceau J, et al: Three-dimensional movements of the upper cervical spine. Spine 13:726-730, 1988

25. Paramore CG, Dickman CA, Sonntag VKH: The anatomic suitability of the C1-2 complex for transarticular screw fixation. J Neurosurg 85:221-224, 1996

26. Steinberg GK, Drake CG, Peerless SJ: Deliberate basilar or vertebral artery occlusion in the treatment of intracranial aneurysms. Immediate results and long-term outcome in 201 patients. J Neurosurg 79:161-173, 1993

27. Stillerman CB, Wilson JA: Atlanto-axial stabilization with posterior transarticular screw fixation: technical description and report of 22 cases. Neurosurgery 32:948-955, 1993

28. Taveras JM, Wood EH: Diagnostic Neuroradiology, ed 2. Baltimore: Williams \& Wilkins, 1976 29. Tokuda K, Miyasaka K, Abe H, et al: Anomalous atlantoaxial portions of vertebral and posterior inferior cerebellar arteries. Neuroradiology 27:410-413, 1985

30. Welch WC, Subach BR, Pollack IF, et al: Frameless stereotactic guidance for surgery of the upper cervical spine. Neurosurgery 40:958-964, 1997

31. Yee LF, Olcott EW, Knudson MM, et al: Extraluminal, transluminal, and observational treatment for vertebral artery injuries. J Trauma 39:480-486, 1995 
Manuscript received August 7, 1997.

Accepted in final form October 31, 1997.

Address reprint requests to: Carl Lauryssen, M.D., Department of Neurosurgery, Washington University School of Medicine, Campus Box 8057, 660 South Euclid Avenue, St. Louis, Missouri 63110. 